\title{
Crossed optic ataxia: possible role of the dorsal splenium
}

\author{
JOSÉ M FERRO, ${ }^{*}$ JM BRAVO-MARQUES, ${ }^{*}$ A CASTRO-CALDAS, ${ }^{*}$ LOBO ANTUNES $\dagger$ \\ From the Language Research Laboratory* and the Neuropathology Laboratory, $\dagger$ Centro de Estudos Egas \\ Moniz (INIC), Department of Neurology, Hospital de Santa Maria, Lisbon, Portugal
}

SUMMARY An unusual combination of disconnective syndromes is reported: transcortical motor aphasia, left arm apraxia and optic ataxia. Neuropathological examination showed a left parieto-occipital and a subcortical frontal infarct and a lesion of the dorsal part of the posterior two-fifths of the callosum. The frontal lesion caused the transcortical motor aphasia and produced the left arm apraxia. Visuomotor incoordination in the right hemispace was due to the left parieto-occipital infarct, while the crossed optic ataxia in the left hemispace was attributed to the callosal lesion. It is proposed that the pathway that serves crossed visual reaching passes through the dorsal part of the posterior callosum. This case reinforces the growing evidence that fibres in the corpus callosum are arranged in ventro-dorsal functional lamination.

Optic ataxia or visuomotor ataxia ${ }^{1}$ consists of a disturbance in reaching under visual control that may affect one or both hands, and be present either in the whole or in part of the visual fields. A probable explanation for this defect is a disconnection between the visual and motor areas, in such a way that visual perception, naming, and reading are possible, although visual information cannot gain access to the hand motor areas in order to steer manual reaching. This explanation was supported by the experimental study of Haaxma and Kuypers ${ }^{2}$ who could disturb visual guided hand movements by means of a parietal leucotomy in the split-brain monkey. The reports by Castaigne and associates ${ }^{34}$ of visual ataxia following surgical section of the parietooccipital junction, which severed association fibres between the occipital and frontal lobes, are also in keeping with this view. It is suggested from these studies that the pathway subserving visuomotor behaviour connects the occipital with the frontal lobe and crosses through the posterior parietal lobe.

The pathway connecting the visual areas of one hemisphere with the contralateral motor and premotor areas (in which a lesion, according to Rondot,

Address for reprint requests: José M Ferro, MD, Neurobehavioral Unit, Centro de Estudos Egas Moniz, Hospital Santa Maria, 1600 Lisboa, Portugal.

Received 14 May 1982 and in revised form 23 January 1983. Accepted 7 February 1983
Recondo and Dumas ${ }^{1}$, induces a crossed optic ataxia, that is, inability to reach in one hemifield with the hand of the opposite side) is, according to most animal studies, via the callosum..$^{5-9}$ Further, it appears that adequate interhemispheric transmission for the visual control of the ipsilateral hand and fingers is effected by the splenium. ${ }^{10}$ Evidence from clinical studies is scanty because the majority of cases of optic ataxia which underwent anatomical study had bilateral optic ataxia and bilateral parieto-occipital lesions. ${ }^{1}$ Stenvers ${ }^{11}$ stated that for crossed visuomotor reaching, visual information could travel from the occipital to the ipsilateral frontal lobe and then to the contralateral one, crossing the anterior callosum (case 34 ) or be transferred from one occipital lobe to the opposite, via the posterior callosum, and then, ipsilaterally, to the frontal lobe. Indeed, crossed visuomotor ataxia in Boller' $\mathrm{s}^{12}$ case is explained by lesions severing both pathways. In the present clinico-pathological study we propose that the pathway that serves crossed visuomotor control travels through the dorsal part of the posterior callosum.

\section{Case report}

A 73-year-old right-handed woman had speech and visual disturbances and slight right-sided weakness of sudden onset. Blood pressure was $100 / 70 \mathrm{mmHg}$, the pulse was irregular with premature beats, and a systolic blowing murmur was heard in the aortic area. There was a slight 
right-sided weakness which did not prevent the patient from using objects or making independent movements of the fingers. Tendon reflexes were brisker on that side. No pain, touch or postural sensory defects were detected. When assessed with a standardised aphasia battery, ${ }^{13}$ her spotaneous speech was non-fluent, with a few literal paraphasias and occasional echolalia, but without articulatory defect. Serial and automatic speech were normal. Visual and tactile (both hands) naming was impaired. Visual object identification by name was normal and she could follow simple and most two-step verbal commands. She could easily repeat words, sentences and three-digit series. Her language disturbance was thus classified as a moderate transcortical motor aphasia. Although she could read aloud some words, matching written words to objects and following written commands was impaired. Spelling was also disturbed and she never showed a letter-by-letter approach when reading single words. She displayed "multiple-loop" agraphia. Drawing was disturbed bilaterally. The left hand was grossly apraxic: on verbal command and imitation, symbolic gestures and manipulation of objects were impaired, while with the right hand both symbolic gestures and actual use of objects were easily performed. She presented a right homonymous hemianopia when tested by confrontation, but her speech disturbance precluded perimetric visual field examination. On the left, the "threat reflex" was normal, but on the right blinking was not always obtained and she did not try to overcome the visual field defect by moving her head. Conjugate ocular movements were full on verbal command. Saccadic pursuit to the left was normal, while it was diminished to the right. Ocular fixation was normal. In the left visual hemispace, gaze was well oriented towards new targets, but sometimes after a delay. Manual reaching under visual control was disturbed. The patient was not able to reach objects placed in the right hemispace, either with the left or the right hand, even when she gazed at them. (We use the term hemispace as defined by Heilman and Valenstein ${ }^{14}$ : the space to one side of the midline of the body.) She oriented her arms randomly to the right, making grasping movements with the hand. In the left hemispace, whether or not she fixated the targets, her left hand could always grasp them. Her right hand, even when the patient was looking at the objects, could not reach them. The arm was correctly oriented, but the extended fingers made slight flexor movements around the target, generally stopping before or behind, but sometimes over it, or to its left or right. If by chance, her right hand bumped the object or the examiner's arm, she groped palpating until she succeded in grasping the object. She could, when requested, place her right hand on her head, on her left hand or, with slight hesitations, on her ears. Using the left hand she could catch the right one and clap hands. When trying to cut a sheet of paper held in the left hand with scissors held by the right hand, the scissors did not "find" the paper, but as soon as they came into contact, several strips of paper were easily cut.

During the following month the right hemiparesis cleared although a slight right hypereflexia remained. Speech disturbance improved, but some loss of fluency on spontaneous speech and a naming disturbance were still detected. Visual field, oculomotor and visual guided reach- ing defects persisted unchanged. On the 38th day of her stay in the hospital the patient's condition deteriorated with the sudden appearance of coma and cardiogenic shock. She died a few hours later.

\section{Pathological study}

Necropsy revealed severe generalised atherosclerosis, with thrombosis of both coronary arteries and several foci of myocardial infarction, including a large recent posteroinferior necrosis of the ventricular wall. Atherosclerotic lesions were also extensive in the aortic arch, basal cerebral vessels, vertebral and basilar arteries. Inspection of the brain, after fixation in $10 \%$ formalin for 6 weeks, showed a moderate degree of frontal atrophy and a large softened area in the medial left occipital lobe that extended from the occipital pole to the parieto-occipital junction and to the dorsal aspect of the posterior two-fifths of the corpus callosum. The hemispheres were sectioned from the frontal to the occipital pole in serial coronal slices, approximately 1 $\mathrm{cm}$ thick. Softening involved both margins of the calcarine fissure, the cuneus, the precuneus, the posterior part of the superior parietal gyrus and the subjacent white matter up to the occipital horn of the lateral ventricle (figs 1 and 2). The convolutions of the external face of the hemisphere and the fusiform gyrus were spared. The lingual gyrus was involved only in its posterior tip.

Myelin and haematoxylin-eosin stained paraffinembedded histological sections confirmed the macroscopic observations. The softened area showed numerous foamy compound granular corpuscles and peripheral glial and connective proliferation. Two other areas of infarction were found in the left hemisphere: one in Ammon's horn, and another in the frontal lobe white-matter. The latter extended from 3.5 to $7.5 \mathrm{~cm}$ behind the frontal pole, was rounded ( $8 \mathrm{~mm}$ diameter) and was located between the superior occipito-frontal fasciculus medially, and the superior longitudinal fasciculus, laterally. This lesion also severed tapetum fibres joining premotor areas and in part, pyramidal fibres on their way to the internal capsule. Necrosis of the corpus callosum was restricted to the dorsal splenium and to a thin band in the posterior third of the dorsal aspect of the body (fig 3). Some cortical laminar necrosis, bilateral scattered, were found. This was probably related to the terminal events. No other lesions were found in the right hemisphere.

\section{Discussion}

This patient presented an unusual clinical picture consisting of a combination of disconnection syndromes: transcortical motor aphasia, left limb apraxia and optic ataxia, which can be understood on the basis of the necropsy findings.

The subcortical left frontal lesion sparing Broca's area and the superior longitudinal fasciculus, prevented communication between the "frontal ideational field" 15 and Broca's area, and was responsible for the transcortical motor aphasia. The same frontal lesion was also located between the left premotor 


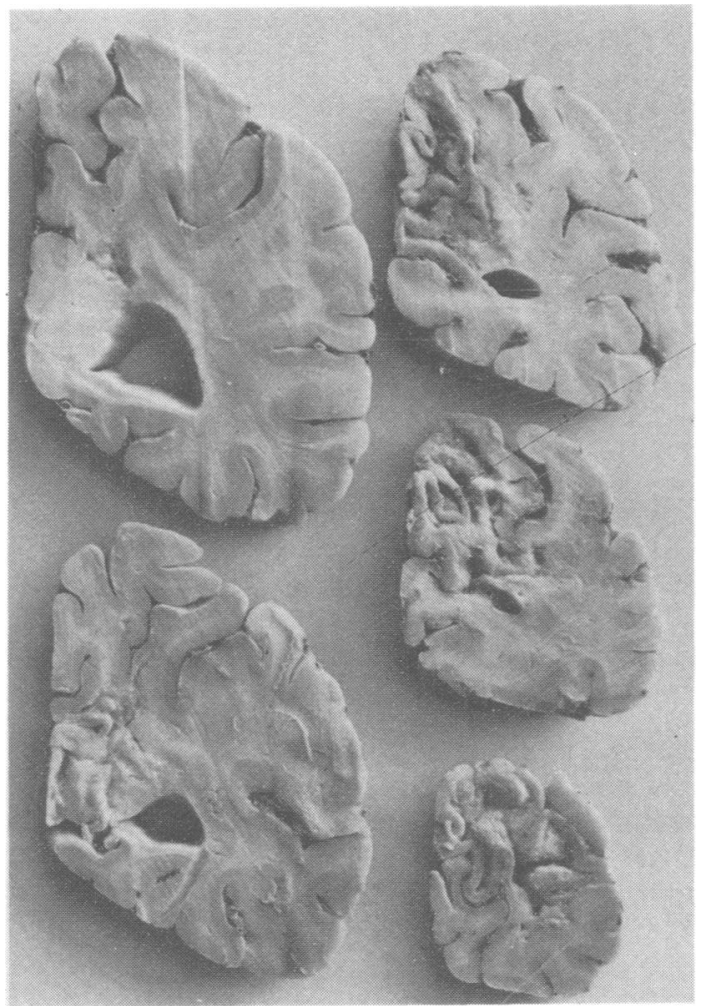

Fig 1 Serial coronal sections of the left hemisphere (first section made $1 \mathrm{~cm}$ from the occipital pole) showing the extent of the parieto-occipital softening. Note the supero-medial location of the infarct.

area and the anterior half of the corpus callosum, where commissural fibres joining homotopic parts of premotor areas are known to travel, ${ }^{16}$ preventing motor programmes generated in left frontal areas from reaching the same areas of the opposite hemisphere, thus producing a left arm apraxia. ${ }^{17}$

The patient had a bi-manual visuomotor incoordination in her right hemispace and a crossed, that is, right hand, visuomotor ataxia in her left halfspace. Although visual field defects due to geniculo-striate lesions do not prevent localisation in the extrapersonal space,,$^{18}$ there is general agreement that it is a necessary condition for the diagnosis of optic ataxia that the visual field where the ataxia occurs be intact. ${ }^{19}$ Thus, visuomotor incoordination in the right hemispace can be secondary to right hemianopia. These signs were due to the large left occipito-posterior parietal infarct. Indeed, this area is crucial for the exploration of extrapersonal space $^{20-22}$ and lesions of the occipito-parietal junction and posterior parietal lobe have been associated

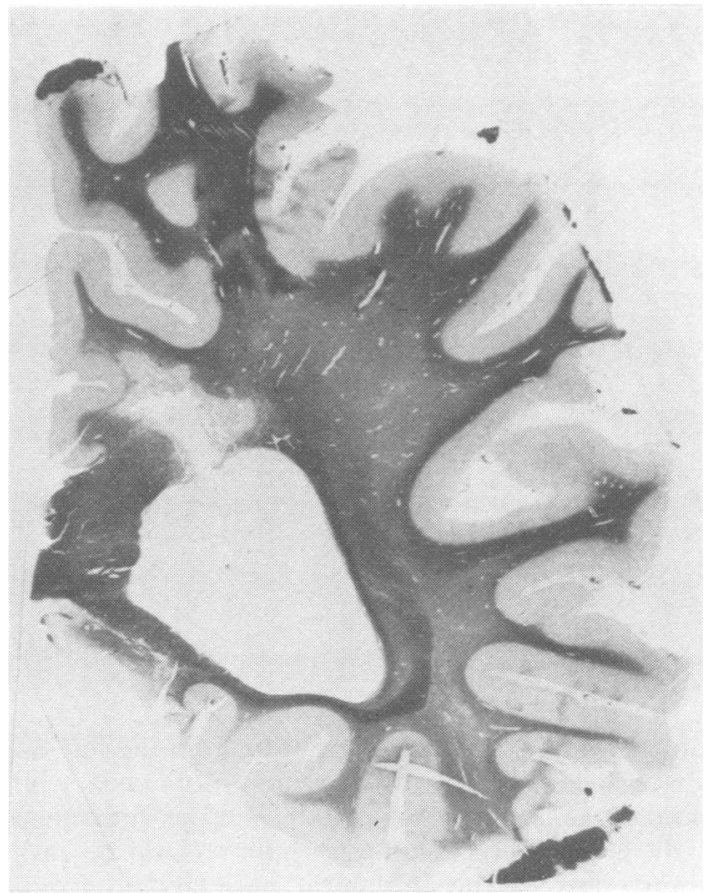

Fig 2 Myelin stain (coronal section $5.5 \mathrm{~cm}$ from the occipital pole) of the anterior extremity of the parieto-occipital infarct. Demyelination involves the dorsal radiations of the splenium, sparing the ventral ones.

with visuomotor ataxia in the contralateral hemispace. ${ }^{1}$

Left crossed optic ataxia, that is, right hand ataxia in the left hemispace is the most interesting finding in this patient. As the left hand visuomotor coordination in this half space was normal, defects in visual perception, visual attention and oculomotor impairment can be excluded as the cause of left crossed optic ataxia. The mild weakness of the right hand cannot explain it, because this hand could make independent movements of the fingers, use objects, perform symbolic gestures and be directed towards body parts. There were no defects of postural sense, and a general disturbance of extrapersonal spatial localisation cannot explain why the left optic ataxia was restricted to the right hand. In this patient the necrosis of the corpus callosum was limited to the superior part of its posterior twofifths. The dorsal radiations of the splenium were severely disrupted by the left subcortical parietal lesion, while the ventral radiations were intact. This lesion prevented visual information concerning localisation in the left hemifield from crossing the callosum and reaching left parietal areas where it would be integrated with somatosensory informa- 


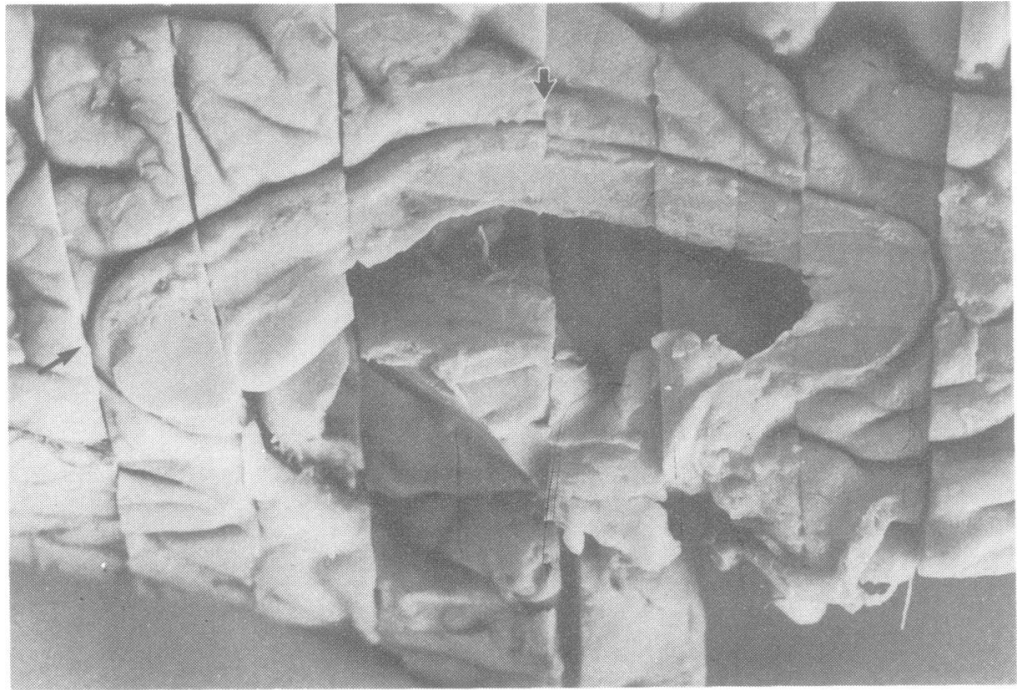

Fig 3 Longitudinal section of the callosum, showing softening of the dorsal splenium (large arrow). The small arrow points to the anterior limit of the necrosis in the body, as determined by microscopic examination. tion, in order to steer the right hand in the left-half space. It caused the crossed visuomotor ataxia, while direct reaching was preserved, as in the undamaged right hemisphere visual information could be easily transferred to the ipsilateral parietal and frontal lobes. The right hand could accurately be placed on the left hand, a movement that needs anterior callosal crossing, but no visual control. If the anterior callosal pathway proposed by Stenvers ${ }^{11}$ were an active one, visuo-spatial information from the left hemifield could travel from the left frontal lobe through the anterior callosum and left crossed visuomotor ataxia would no longer be present. Frontal lobe lesions do not seem to cause this visuomotor disturbance. The defect was restricted to the visual modality and the right hand could be driven by somatosensory information as when touching body parts. Complex learned movements such as symbolic gestures and object manipulation were well performed by this hand, indicating that connections between parietal and premotor areas were functionally preserved. Moreover the subcortical frontal lesion spared the superior occipito-frontal fasciculus which is the main connection between the occipital and the frontal lobe. In the monkey, premotor lesions can disturb visual guided behaviour producing difficulty in suppressing a tendency to reach straight to a target, ${ }^{23}$ a defect that can be explained as an inability to adapt a motor programme to a new situation. In humans, although some anatomically verified cases of cptic ataxia had frontal lesions ${ }^{24-27}$ all these patients had also bilateral parieto-occipital lesions and their visuomotor disturbance was identical to that displayed by patients with lesions restricted to the parieto-occipital regions. Lesions restricted to the frontal lobes have been associated with apraxia of gaze $^{28}$ and tonic perseveration of gaze $^{29}$ but not with optic ataxia. Ratcliff and Davies-Jones $^{30}$ also found no subject with a lesion in the anterior part of the brain that showed defective localisation in any quadrant.

From this and reported cases of optic ataxia it is possible to map the pathway that serves crossed visuomotor behaviour.

Figure 4 shows that the type of visuomotor ataxia changes with the location of the lesion in this pathway and its relation with the direct pathway. A unilateral occipital or posterior parietal lobe lesion $^{31} 32$ damages the origin of both the direct and crossed pathways and causes direct and crossed optic ataxia in the controlateral half-field (fig 4-1, 2). A subcortical lesion high in the parieto-occipital junction can damage only the direct pathway and produce direct optic ataxia in the controlateral half-field ${ }^{4}$ (fig 4-3) while a more extensive lesion in the same location can produce both direct and crossed optic ataxia by damaging both pathways ${ }^{3}$ (fig 4-4). A subcortical lesion near to the splenium would interrupt only the crossed pathway (fig 4-5). Such a lesion causes crossed visuomotor ataxia in the controlateral hemifield. ${ }^{11}$ A callosal section ${ }^{33}{ }^{34}$ severing both crossed pathways produced a bilateral crossed visuomotor incoordination (fig 4-6). More limited callosal lesion affecting its posterior part were found in Boller's case ${ }^{12}$ (fig 4-7), in the present case and in Stenvers' case 49 (fig 4-8). Stenvers' patient had a posterior callosal section to remove a left occipital mass and presented bilateral crossed optic ataxia combined with a ipsilateral direct one. ${ }^{11}$ A superior parietal lobule lesion ${ }^{35}$ produces a bilat- 


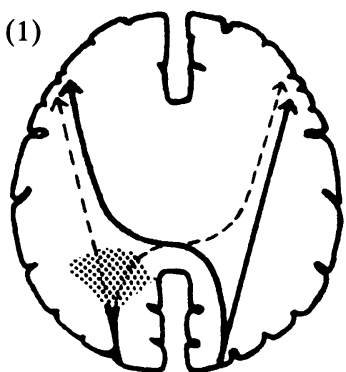

Riddoch, 1935

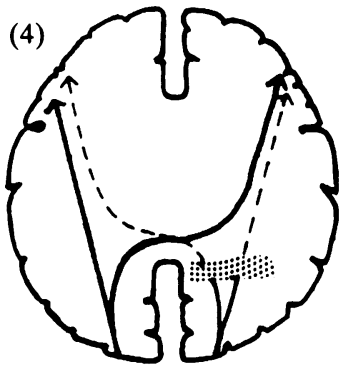

Castaigne et al, 1971

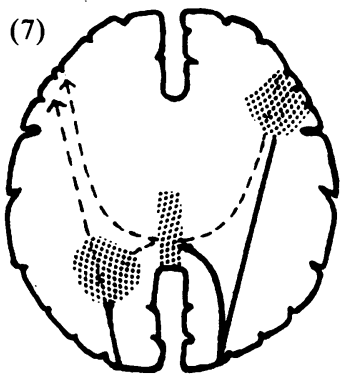

Boller et al , 1975

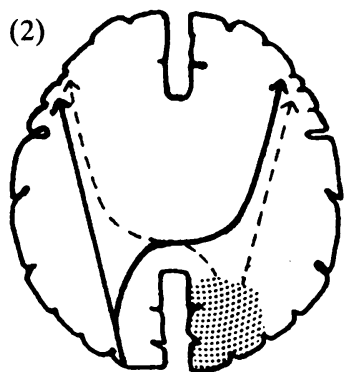

Marti Masso et al, 1978

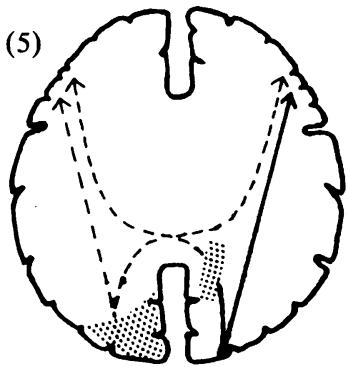

Stenvers, case 37,1961

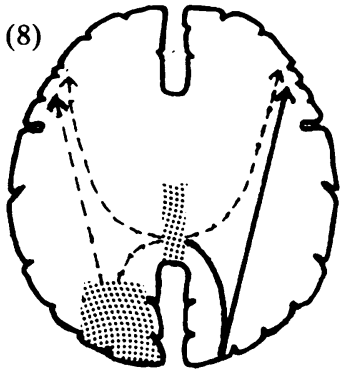

Stenvers, case 49

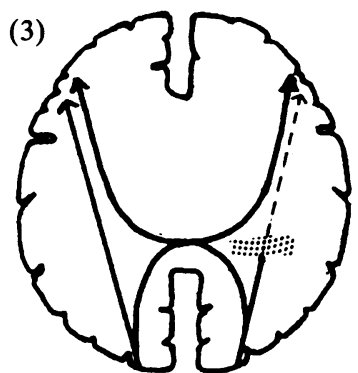

Castaigne et al. 1975
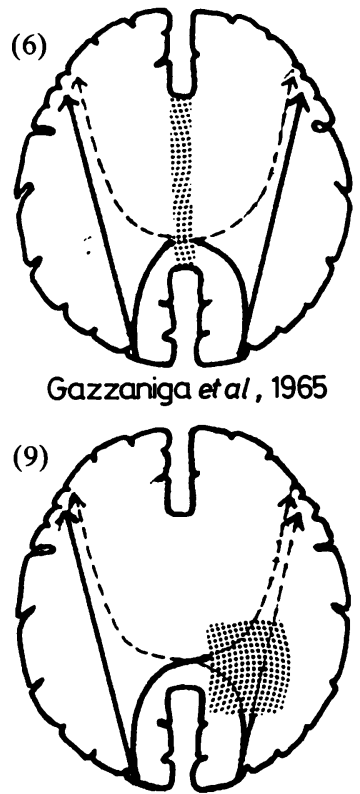

Levine et al, 1978

Ferro et al (present case)

Fig 4 Schematic representation of lesions (dark areas) in several cases of optic ataxia. Continuous lines indicate the proposed normal direct and crossed pathways used in visuomotor behaviour. Discontinuous lines indicate damaged pathways.

eral disturbance of manual reaching with the controlateral hand and a crossed one for the ipsilateral hand. Such a lesion disrupts integration of visual information from both half-fields with somaesthetic data concerning the controlateral hand and can prevent interhemispheric transmission of visual information from the ipsilateral visual cortex (fig 4-9).

Evidence from two sources seems to contradict the proposed role of the posterior callosum in crossed visuomotor coordination. Thus, visuomotor ataxia has not been described in cases of alexia without agraphia (see Benson and Geschwind ${ }^{36}$ and Michel et al, ${ }^{37}$ for review) or surgical section of the posterior callosum. ${ }^{38-42}$ We cannot exclude the possibility that visuomotor incoordination might have been demonstrated if special tests of visuomotor control were used.

Cumming and associates ${ }^{43}$ reported a case of alexia without agraphia caused by an infarction in the left occipital lobe and splenium who performed poorly with his right hand in a visual tracking task. However the absence of visuomotor ataxia in cases of surgical section may be due to the fact that the lesions of the callosum were restricted to its caudal one or two centimeters, so as to allow some transfer of visual information. In fact, the middle third of the callosum also participates in the interhemispheric transfer of visuopatial information. ${ }^{44}$ In alexia with- 
out agraphia the callosal lesion is either absent $t^{45}$ or confined to the splenium. The splenium lesion can be incomplete, severing only its ventral aspect ${ }^{46-48}$ or the ventral part of the forceps minor ${ }^{464950}$ sparing its dorsal aspect whose integrity seems necessary to visuomotor interhemispheric integration. In man the complete section of the corpus callosum causes a transient bi-crossed visuomotor incoordination..$^{334}$ Gazzaniga $^{33}$ stresses the role of cross-cued information, especially eye position, in the overcoming of visuomotor incoordination, after complete commissurotomy. Recently Volpe and associates ${ }^{51}$ suggested that for visual non-verbal information the posterior $3 \mathrm{~cm}$ of corpus callosum is necessary for control of the ipsilateral hand. In fact this limited callosal section disrupts crossed visuomotor control. This defect is not aggravated by splitting of the remaining callosum or anterior commissurotomy. ${ }^{51}$

It is also possible that the absence of optic ataxia in these cases may be due to the activity of ancillary pathways. Two main alternative routes are possible: (1) interhemispheric transfer of visual information through the anterior callosum, (2) control of the hand by the ipsilateral parietal lobe. Hypothesis (1) does not explain why the complete surgical section of the callosum does not cause a full-blown picture of optic ataxia or why our patient or Stenvers' case 49 , whose callosal lesions were restricted to its posterior part presented a crossed optic ataxia. These facts are explained by hypothesis (2). Indeed, only the combination of a posterior callosal lesion with a parieto-occipital lesion would impair interhemispheric transfer of visuo-spatial information and preclude the damaged posterior parietal lobe from steering the ipsilateral hand, thus causing a clinical impressive and stable crossed optic ataxia. Animal experiments are in accordance with this view: in the monkey the effect of callosal section is also transitory and the visual and motor systems of one side can regain control of the ipsilateral limb ${ }^{9}$ by way of descending connexions, namely the ventro-medial brain stem system. ${ }^{10}$ Also neurophysiological studies $^{2021}$ have found most cells in the posterior parietal lobe to fire in relation to ipsilateral hand movements. Furthermore it has been suggested that in man abductive movements would depend on a controlateral command, while abductive movements, such as those needed for crossed reaching, would have a bihemispheric control. ${ }^{52}$

The fact that in our patient the callosal lesion was confined to the dorsal aspect of the posterior callosum and to its dorsal forceps agrees with the finding of restricted ventral lesions of the splenium in some cases of alexia without agraphia..$^{46-48}$ It is probable that fibres in the corpus callosum are not only distributed topographically in an anterio- posterior arrangement ${ }^{53}$ but also following a ventro-dorsal lamination. In the posterior callosum one would find from the bottom to the top, fibres conveying information about letters, colours and visuo-spatial localisation.

The authors thank Dr Pereira Miguel and the Department of Medicine IV (Professor Fernando Padua) who referred the patient to our Laboratory.

\section{References}

' Rondot P, De Recondo J, Dumas JLR. Visuomotor ataxia. Brain 1977;100:355-76.

${ }^{2}$ Haaxma R, Kuypers HGJM. Intrahemispheric cortical connexions and visual guidance of hand and finger movements in the rhesus monkey. Brain 1975;98:239-60.

${ }^{3}$ Castaigne P, Pertuiset B, Rondot P, De Recondo J. Ataxie optique dans les deux hémichamps visuels homonymes gauches aprés exérèse chirurgicale d'un anéurysme arteriel de la paroi du ventricule latéral. Rev Neurol (Paris) 1971;124:261-8.

${ }^{4}$ Castaigne P, Rondot P, Dumas JLR, Tempier P. Ataxie optique localisée au coté gauche dans les deux hemichamps visuels homonymes gauches. Rev Neurol (Paris) 1975;131:23-8.

${ }^{5}$ Downer JL de C. Changes in visually guided behaviour following mid saggital division of optic chiasma and corpus callosum in monkey (Macaca mulatta). Brain 1959;82:251-9.

- Gazzaniga MS. Visuomotor integration in split-brain monkeys with other cerebral lesions. Exp Neurol 1966;16:289-98.

${ }^{7}$ Lehman RAW. Motor coordination and hand preference after lesions of the visual pathway and corpus callosum. Brain 1968;91:523-38.

${ }^{8}$ Lund JS, Downer JL de C, Lumley JSP. Visual control of limb movement following section of optic chiasm and corpus callosum in the monkey. Cortex 1970;6:32346.

${ }^{9}$ Keating EG. Loss of visual control of the forelimb after interruption of cortical pathways. Exp Neurol 1973;41:638-48.

${ }^{10}$ Brinkman J, Kuypers HGJM. Cerebral control of contralateral and ipsilateral arm, hand and finger movements in the split-brain rhesus monkey. Brain 1973;96:653-74.

"Stenvers HW. Les Réactions Opto-motrices. Contribution a l'étude des functions du cerveau. Paris: Masson et Cie, 1961.

12 Boller F, Cole M, Kim Y, Mack JL, Patarawan C. Optic ataxia: clinical-radiological correlations with the EMI scan. J Neurol Neurosurg Psychiatry 1975;38:954-8.

${ }^{13}$ Ferro JM, Santos ME, Castro Caldas A, Mariano MG. Gesture recognition in aphasia. J Clin Neuropsychol 1980;2:277-92.

${ }^{14}$ Heilman KM, Valenstein E. Mechanisms underlying hemispatial neglect. Ann Neurol 1979;5:166-70.

15 Goldstein K. Language and Language Disturbance. New York: Grune and Stratton, 1948. 
${ }^{16}$ Pandya DN, Vignolo LA. Intra and interhemispheric projections of the precentral, premotor and arcuate areas in the Rhesus Monkey. Brain Res 1971;26:217-33.

${ }^{17}$ Liepman H. Der Weitere Krankheitsverlauf bei dem Einseitig Apraktischen un der Gehirnbefund auf Grund von Serienschnitten. Berlin: Verlag "Von S Kargẹr, 1906.

${ }^{18}$ Perenin MT, Jeannerod M. Residual vision in cortically blind hemifields. Neuropsychologia. 1975;13:1-7.

${ }^{19}$ Rondot P, De Recondo J. Ataxie optique: trouble de la coordination visuomotrice. Brain Res 1974;71:36775.

${ }^{20}$ Hyvären J, Poranen A. Function of the parietal associative area 7 as revealed from cellular discharges in alert monkeys. Brain 1974;97:673-92.

${ }^{21}$ Mountcastle VB, Lynch JC, Georgopoulos A, Sakata H, Acuna C. Posterior parietal association cortex of the monkey: command functions for operations within extrapersonal space. J Neurophysiol 1975;38:871-908.

${ }^{22}$ Robinson DL, Goldberg ME, Stanton GB. Parietal association cortex in the primate: sensory mechanisms and behavioral modulation. J Neurophysiol 1978;41:910-32.

${ }^{23}$ Moll L, Kuypers HGJM. Premotor cortical ablations in monkeys: contralateral changes in visually guided reaching behaviour. Science 1977;198:317-9.

${ }^{24}$ Hécaen H, Ajuriaguerra J de, Rouquès L, David M, Dell MB. Paralysie psychique du regard de Balint au cours de l'évolution d'une leucoencephalite type Balo. Rev Neurol (Paris) 1950;83:81-104.

${ }^{25}$ Hecaen $\mathrm{H}$, Ajuriaguerra $\mathrm{J}$ de. Balint's syndrome (psychic paralysis of visual fixation) and its minor forms. Brain 1954;77:373-400.

${ }^{26}$ Michel F, Jeannerod M, Devic M. Troubles de l'orientation visuelle dans les trois dimensions de l'espace (à propos d'un cas anatomique). Cortex 1965;1:441-66.

${ }^{27}$ Gloning I, Gloning K, Hoff H. Neuropsychological symptoms and syndromes in lesions of the occipital lobe and the adjacent areas. Paris: Gauthier-Villars, 1968.

${ }^{28}$ Alajouanine T, Thurel R. Révision des paralysies des mouvements asscoiés des globes oculaires. Rev Neurol (Paris) 1931;1:125-69.

${ }^{29}$ Botez MI. Clinical contributions to the study of the tumoral frontal syndrome. Psychiat Neurol (Basel) 1960;140:351-68.

${ }^{30}$ Ratcliff G, Davies-Jones GAB. Defective visual localization in focal brain wounds. Brain 1972;95:49-60.

${ }^{31}$ Riddoch G. Visual disorientation in homonymous halffields. Brain 1935;58:376-82.

${ }^{32}$ Marti Masso JF, Carrera N, Obeso J, Astudillo W, De la Puente E, Bastera C. Distintas variedades de ataxia visuomotora. In: Espadater JM, Oliveilla J, eds. II Congresso Ibero-Americano de Neurologia. Resumenes de Ponencies y Communicaciones. Barcelona, 1978:47.

${ }^{33}$ Gazzaniga MS. Eye position and visual motor coordination. Neuropsychologia 1969;7:379-82.

${ }^{34}$ Gazzaniga MS, Bogen JE, Sperry RW. Observations on visual perception after disconnexion of the cerebral hemispheres in man. Brain 1965;88:221-36.
${ }^{35}$ Levine DN, Kevin JK, Mohr JP. Inaccurate reaching associated with a superior parietal lobe tumor. Neurology (Minneap) 1978;28:556-61.

${ }^{36}$ Benson DF, Geschwind N Alexias. In: Vinken BJ, Bruyn GW, eds. Handbook of Clinical Neurology. Amsterdam: North-Holland Publishing Company, 1969: vol. 4, 7, 112-40.

${ }^{37}$ Michel F, Schott B, Boucher M, Kopp N. Alexie sans agraphie chez un malade ayant un hémisphère gauche déafferenté. Rev Neurol (Paris) 1979;135:347-64.

${ }^{38}$ Gazzaniga MS, Freedman H. Observations on visual processes after posterior callosal section. Neurology (Minneap) 1973;23:1126-30.

${ }^{39}$ Treschner JH, Ford RF. Colloid cyst of the third ventricle. Arch Neurol Psychiatry 1937;37:959-73.

${ }^{40}$ Maspes PE. Le syndrome experimental chez l'homme de la section du splenium du corps calleux. Alexie visuelle pure hemianopsique. Rev Neurol (Paris) 1948;80:100-13.

${ }^{41}$ Iwata M, Sugishita M, Toyokura Y, Yamada R, Yoshioka M. Etude sur le syndrome de disconnexion visuo-linguale aprés la transection du splenium du corps calleux. J Neurol Sci 1974;23:421-32.

${ }^{42}$ Damásio AR, Chui HC, Corbett J, Kassel N. Posterior callosal section in a non-epileptic patient. $J$ Neurol Neurosurg Psychiatry 1980;43:351-6.

${ }^{43}$ Cumming WJK, Hurwitz LJ, Perl NT. A study of a patient who had alexia without agraphia. J Neurol Neurosurg Psychiatry 1970;33:34-9.

${ }^{44}$ Dimond SJ, Scammel RE, Brouwers EYM, Weeks R. Functions of the centre section (trunk) of the corpus callosum in man. Brain 1977;100:543-62.

${ }^{45}$ Hécaen H, Gruner J. Alexie "pure" avec intégrité du corps calleux. In: Michel F, Schott B, eds. Les syndromes de disconnexion calleuse chez l'homme. Acte du Colloque International de Lyon. Lyon 1975, 416.

${ }^{46}$ Déjérine J. Contribution à l'étude anatomopathologique et clinique des différentes variétés de cécité verbale. Mem Soc Biol 1982;4:61-90.

${ }^{47}$ Benson DF, Segarra J, Albert ML. Visual agnosiaprosopagnosia. Arch Neurol 1974;30:307-10.

${ }^{48}$ Ajax ET, Schenkenberg T, Kosteljanetz M. Alexia without agraphia and the inferior splenium. Neurology (Minneap) 1977;27:685-8.

${ }^{49}$ Geschwind N, Fusillo M. Color naming defects in association with alexia. Arch Neurol 1966;15:137-46.

${ }^{50}$ Greenbralt SH. Alexia without agraphia or hemianopsia. Anatomical analysis of an autopsied case. Brain 1973;96:307-16.

${ }^{51}$ Volpe BT, Sidtis JJ, Holtzman JD, Wilson DW, Gazzaniga MS. Cortical mechanisms involved in praxis: observations following partial and complete section of the corpus callosum in man. Neurology (NY) 1981;32:645-50.

52 Van der Staak C. Intra and interhemispheric visualmotor control of human arm movements. Neuropsychologia 1975;13:439-48.

${ }^{33}$ Pandya DN, Karol EA, Heilbronn D. The topographic distribution of interhemispheric projections in the corpus callosum of the rhesus monkey. Brain Res $1971 ; 32: 31-43$. 